\title{
Polymerase chain reaction-based screening for the ceftriaxone-resistant Neisseria gonorrhoeae F89 strain
}

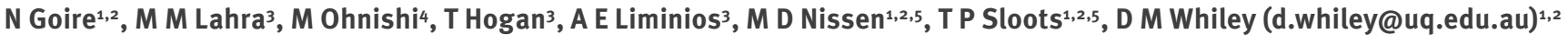

1. Queensland Paediatric Infectious Diseases Laboratory, Queensland Children's Medical Research Institute, The University of Queensland, Queensland, Australia

2. Sir Albert Sakzewski Virus Research Centre, Children's Health Service, Queensland, Australia

3. WHO Collaborating Centre for STD, Microbiology Department, South Eastern Area Laboratory Services, The Prince of Wales Hospital, Sydney, New South Wales, Australia

4. National Institute of Infectious Diseases, Tokyo, Japan

5. Microbiology Division, Pathology Queensland Central Laboratory, Herston, Queensland, Australia

Citation style for this article:

Goire N, Lahra MM, Ohnishi M, Hogan T, Liminios AE, Nissen MD, Sloots TP, Whiley DM. Polymerase chain reaction-based screening for the ceftriaxone-resistant

Neisseria gonorrhoeae F89 strain. Euro Surveill. 2013;18(14):pii=20444. Available online: http://www.eurosurveillance.org/ViewArticle.aspx?Articleld=20444

Article submitted on 23 October 2012 / published on 04 April 2013

Emergence and spread of Neisseria gonorrhoeae resistant to extended spectrum cephalosporins is a major problem threatening treatment of gonorrhoea and is further highlighted by the recent report of a second ceftriaxone-resistant $N$. gonorrhoeae strain (F89) in Europe, initially observed in France and subsequently identified in Spain. N. gonorrhoeae antimicrobial resistance (AMR) surveillance has acquired new importance and molecular tools have the potential to enhance bacterial culture-based methods. In this study, we established a polymerase chain reaction (PCR) protocol for direct detection of the F89 strain. A key component of this screening protocol was the development of a hybridisation probe-based melting curve analysis assay (mosaic501-hybPCR) to detect the presence of an $A_{501} \mathrm{P}$ substitution on the $N$. gonorrhoeae mosaic penicillin binding protein 2 ( $\mathrm{PBP} 2)$ sequence, an important characteristic of the F89 strain. The mosaic501-hybPCR was evaluated using plasmid-derived positive controls $(n=3)$ and characterised gonococcal $(n=33)$ and non-gonococcal $(n=58)$ isolates. The protocol was then applied to 159 clinical specimens from Sydney, Australia, collected during the first half of the year 2012 that were N. gonorrhoeae PCR-positive. Overall, the results indicate that the PCR-based protocol is suitable for direct detection of the $N$. gonorrhoeae F89 strain in non-cultured clinical samples. It therefore provides an additional tool to aid investigations into the potential spread of F89 strain throughout Europe and elsewhere.

\section{Introduction}

With the emergence of the ceftriaxone-resistant and extensively-drug resistant (XDR) Neisseria gonorrhoeae strains Ho41 in Japan [1] and F89 in France and Spain $[2,3]$, there exists a real threat that such strains may emerge and spread worldwide. Molecular characterisation of these strains has implicated mutations in the penicillin binding protein $2\left(\mathrm{PBP}_{2}\right)$ in conferring resistance to ceftriaxone $[1,2]$. Notably, the 'mosaic' variant of $\mathrm{PBP}_{2}$ has long been associated with reduced susceptibility to ceftriaxone and other extended spectrum cephalosporins (ESCs), and both the Japanese Ho41 and European F89 strains harboured a mosaic PBP2. In each of these cases however, additional mutations on the mosaic $\mathrm{PBP}_{2}$ were responsible for expression of resistant phenotypes displaying a raised ceftriaxone minimum inhibitory concentration (MIC). The Japanese Ho41 (ceftriaxone $\mathrm{MIC}=2$ to $4 \mathrm{mg} / \mathrm{L}$ ) featured several novel substitutions on the mosaic PBP2, of which two (A311V and T316S) have been experimentally shown to contribute to ESC resistance [1]. Similarly the European F89 strain (ceftriaxone $M I C=1$ to $2 \mathrm{mg} / \mathrm{L}$ ) harboured an amino acid substitution at position 501 (A501P) of the mosaic $\mathrm{PBP}_{2}$, resulting in ESC resistance $[2,3]$. The contribution of other substitutions at position 501 of $\mathrm{PBP}_{2}$, especially $\mathrm{A}_{501 \mathrm{~V}}$ but also $\mathrm{A}_{501 \mathrm{~T}}$, towards reduced susceptibility to ESCs has also been shown [4-7].

N. gonorrhoeae antimicrobial resistance (AMR) surveillance is a pivotal component of public health efforts to control gonorrhoea. Molecular methods for tracking gonococci of major public health importance have considerable potential to enhance $N$. gonorrhoeae AMR surveillance and to this effect we have previously described a rapid real-time polymerase chain reaction (PCR) method for direct detection of the Ho41 strain [8]. In this study we describe a testing algorithm for direct detection of the $N$. gonorrhoeae F89 strain. Briefly, the algorithm involved two steps. The first step screened N. gonorrhoeae nucleic acid amplification test (NAAT)positive specimens for the presence of mosaic PBP2 using a previously described real-time $P C R$ assay (mosaic-PCR; $[9,10]$ ). Samples testing positive by the mosaic-PCR were then subjected to a hybridisation probe-based melting curve analysis assay, developed and validated as part of this study, to characterise the 501 amino acid on the mosaic $\mathrm{PBP}_{2}$ sequence (mosaic501-hybPCR). 
Primers and probes used to analyse Neisseria gonorrhoeae mosaic penicillin binding protein 2 sequences

\begin{tabular}{|c|c|}
\hline Designation & Sequence $\left(5^{\prime} \text { to } 3^{\prime}\right)^{a}$ \\
\hline \multicolumn{2}{|l|}{ Mosaic-PCR } \\
\hline Mosaic-F & GTTGGATGCCCGTACTGGG \\
\hline Mosaic-R & ACCGATTTTGTAAGGCAGGG \\
\hline Mosaic-Probe & FAM-CGGCAAAGTGGATGCAACCGA-BHQ \\
\hline \multicolumn{2}{|l|}{ Mosaic501-hybPCR } \\
\hline Mosaic501-F & GGCGCAAAAACCGGTACG \\
\hline Mosaic501-R & ATCACACGCGGATTTTTAGCC \\
\hline Mosaic501-Probe1 & CGCAAAAACCGGTACGCCG-fluorescein \\
\hline Mosaic501-Probe2 & Quasar 670-GTAAGTTGGTTAACGGTCGTTACGTCGATTACAAACAC-phosphate \\
\hline \multicolumn{2}{|c|}{ Plasmid control development } \\
\hline Control-A501P-F & GGCGCAAAAACCGGTACGCCG \\
\hline Control-A501T-F & GGCGCAAAAACCGGTACGACG \\
\hline Control-A501V-F & GGCGCAAAAACCGGTACGGTG \\
\hline PenA-R & GCCCAAGATGTTCAGGCTGC \\
\hline
\end{tabular}

BHQ: black hole quencher dye; F: forward primer; PCR: polymerase chain reaction; R: reverse primer.

a When present, dye labels or 3' phosphates are also indicated.

\section{Methods}

\section{Mosaic-PCR assay}

The mosaic-PCR was performed using primers and TaqMan probe previously described by Ochiai et al. [10]. Briefly, the reaction mix consisted of $12.5 \mu \mathrm{l}$ of QuantiTect Probe PCR Master Mix (QIAGEN, Doncaster, Australia), 10.0 pmoles each of forward and reverse primer (Mosaic- $\mathrm{F}$ and Mosaic-R; Table 1), 4.0 pmoles of probe (Mosaic-Probe; Table 1) and $2.5 \mu \mathrm{l}$ of sample nucleic acid extract in a final reaction volume of 25.0 $\mu \mathrm{l}$. Reactions were thermo-cycled on a Rotor-Gene 6000 real-time PCR instrument (QIAGEN, Doncaster, Australia) with the following parameters: initial hold at $95^{\circ} \mathrm{C}$ for $15 \mathrm{~min}$ followed by 45 cycles at $95^{\circ} \mathrm{C}$ for $15 \mathrm{sec}$ onds and $60^{\circ} \mathrm{C}$ for 60 seconds. Results were analysed using the quantification analysis tool of the Rotor-Gene software and samples were considered positive if their amplification curves crossed above background fluorescence. We have previously shown this assay to be suitable for direct screening for the $N$. gonorrhoeae mosaic $\mathrm{PBP}_{2}$ sequence directly in non-cultured clinical samples [9].

\section{Mosaic501-hybPCR assay}

The mosaic501-hybPCR was developed as per a modified hybridisation probe-based real-time PCR approach previously described by our laboratory [11]. Briefly, two primers (Mosaic501-F and Mosaic501-R; Table 1) were used for amplification of the target region and two probes (Mosaic501-Probe1 and Mosaic501-Probe2; Table 1) were used for detection, with Mosaic501-Probe1 being the sensor probe and Mosaic501-Probe2 being the anchor probe. In this modified hybridisation probe approach, the Mosaic501-F primer shares the same target sequence as the Mosaic501-Probe1 sensor probe except for the latter 3-base codon representing the 501 amino acid position (Figure). As previously described, this ensures the sensor probe has full homology with its target sequence with the exception of any variations, if present, in the 501 codon of interest [11].

The mosaic501-hybPCR assay was performed using the LightCycler FastStart DNA Master Hybridization Probes kit (Roche Diagnostics, Australia) on a LightCycler 2.0 real-time PCR instrument (Roche Molecular Biochemicals, Mannheim, Germany). Briefly, each LightCycler capillary was loaded with $2 \mu \mathrm{l}$ of $10 \mathrm{x}$ kit Master reagent (Roche Diagnostics, Australia, reagent 1), $1.6 \mu \mathrm{l}$ of $\mathrm{MgCl}_{2}$ (25mM; Roche Diagnostics, Australia, reagent 2), 5.0 pmoles of Mosaic501-F primer (Table 1), 10.0 pmoles of Mosaic501-R primer (Table 1), 2.0 $\mu \mathrm{l}$ of nucleic acid extract or control and made up to a total reaction volume of $20 \mu \mathrm{l}$. Capillaries were then placed into LightCycler centrifuge adapters (Roche Molecular Biochemicals, Mannheim, Germany) and spun in a standard $24 \times 1.5 \mathrm{ml}$ microfuge at approximately $735 \mathrm{~g}$ for 10 seconds. A $2.0 \mu$ l suspension comprising a total of 4.0 pmoles of each probe (Table 1 ) was then added into the sample receptacle of each capillary. The capillaries were then capped but were not microfuged again at this point; this left the PCR reaction in the bottom of the capillary and separated from the probes in the upper receptacle. In this modified hybridisation probe format, the probes must remain separate from the reaction mix during $P C R$ amplification otherwise amplification can be inhibited [11]. 
Alignment of the mosaic501-hybPCR forward primer and hybridisation probes with sequences of Neisseria gonorrhoeae strains harbouring mosaic penicillin binding protein 2 types differing at residue 501

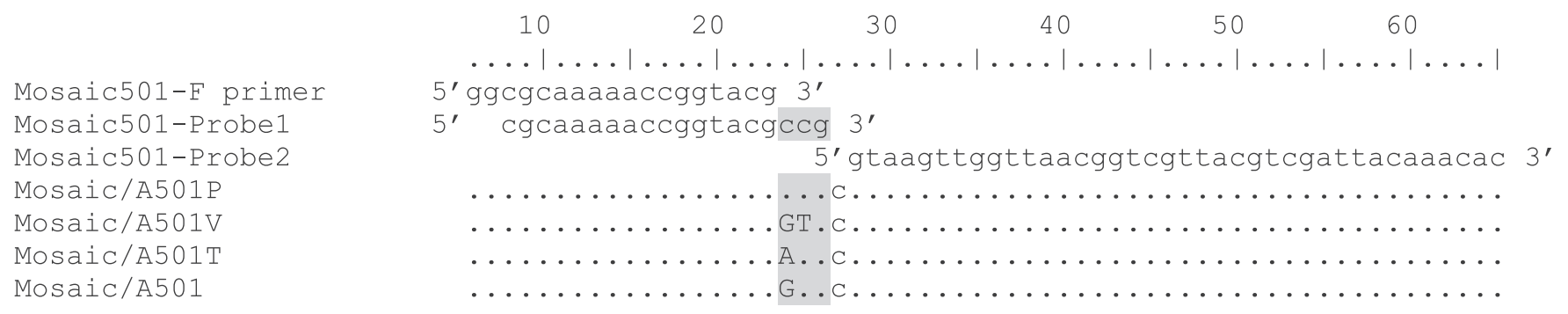

PBP2: penicillin binding protein 2.

The nucleotide sequences of the mosaic PBP2 types are designated by 'mosaic' followed by details of the particular residue or mutation at position 501 of the protein sequence. Nucleotide sequence numbering is based on the first 60 nucleotides of the 107 base pair product obtained in the real-time polymerase chain reaction assay. The codon for the PBP2 '501' amino acid position is represented by nucleotides 19 to 21 . Both probes match $100 \%$ with the mosaic/A501P sequence whereas Mosaic501-probe1 has mismatches with the other PBP 2 types, enabling discrimination by melting curve analysis. Dots indicate sequence identity with the primer or probe sequences. Capitalised bases indicate mismatches with Mosaic501- Probe1.

Amplification was performed on the LightCycler with the following conditions: initial hold at $95^{\circ} \mathrm{C}$ for $10 \mathrm{~min}$ utes followed by 50 cycles at $95^{\circ} \mathrm{C}$ for 10 seconds, $55^{\circ} \mathrm{C}$ for 10 seconds and $72^{\circ} \mathrm{C}$ for 20 seconds. No data collection was conducted during the PCR as the probes were not present in the mix. Following PCR, the capillaries were spun upside down (without the LightCycler centrifuge adapters) in a $24 \times 1.5 \mathrm{ml}$ microfuge at approximately $735 \mathrm{~g}$ for 10 seconds, and then placed back into the LightCycler centrifuge adapters and respun right side up as above. This double spinning was used to wash the probes out of the top of the capillary and bring the whole contents (probes and PCR mix) into the bottom of the capillary. Capillaries were then placed back into the LightCycler and melting curve analysis conducted using the following parameters; $95^{\circ} \mathrm{C}$ for 5 seconds, then the reactions were continuously monitored as they were heated at a rate of $0.2^{\circ} \mathrm{C} /$ second, starting at $40^{\circ} \mathrm{C}$ for 30 seconds to a final temperature of $85^{\circ} \mathrm{C}$.

\section{Assay reference controls}

A mosaic PBP2-harbouring N. gonorrhoeae isolate from a previous study (sequence pattern X; [5]) was used as the positive control for the mosaic-PCR assay. This isolate lacked further alterations at amino acid position 501 (mosaic/A501) and so was also used as the reference control for the mosaic501-hybPCR assay. Given that we did not have access to the $N$. gonorrhoeae F89 strain, which has the sequence encoding the mosaic $\mathrm{PBP}_{2}$ protein with the $\mathrm{A}_{501} \mathrm{P}$ mutation (mosaic/A501P), we had a mosaic/A501P plasmid control (i.e. a mosaic penA sequence with a A501P codon; CCG) synthesised by the University of Queensland Protein Expression Facility (University of Queensland, Australia). The
mosaic/A501 clinical isolate was amplified using primers Control-A501P-F and PenA-R (Table 1). Use of the Control-A501P-F primer, with 'CCG' at the 3'end, enabled the $A_{501} P$ codon to be incorporated into the mosaic $\mathrm{PBP}_{2}$ sequence in the resulting $\mathrm{PCR}$ product. The PCR product was then cloned using the pGEM-T Easy Vector system and the plasmid purified. Plasmid controls were also created for the partial sequences of the mosaic $\mathrm{PBP}_{2}$ harbouring the $\mathrm{A}_{501} \mathrm{~T}$ (mosaic/A501T) and A501V (mosaic/A501V) mutations as described above, using primers Control-A501T-F and ControlA501V-F respectively (Table 1 ).

\section{Mosaic501-hybPCR assay evaluation}

The specificity of the mosaic501-hybPCR assay was investigated using a panel of Neisseria species, comprising both gonococcal $(n=33)$ and non-gonococcal strains $(n=58)$. The $33 N$. gonorrhoeae isolates were of mainly Australian and Asian origin (years of isolation: 1988 to 2009) from a previous study [5], comprising 29 different $N$. gonorrhoeae multi-antigen sequence types (NG-MAST) and 23 different PBP2 types. Four isolates comprised mosaic $\mathrm{PBP}_{2}$ sequences and included the $N$. gonorrhoeae Ho41 strain [1]. Of these four mosaic-harbouring isolates, one isolate also possessed an $\mathrm{A}_{501 \mathrm{~V}}$ alteration (mosaic/A501V) and was the previously described cefixime-resistant NG0304 strain [7], kindly provided by Dr. Makoto Ohnishi, institute of infectious diseases, Japan. The 58 non-gonococcal strains comprised Moraxella catarrhalis $(n=6), M$. osloensis $(n=2), N$. cinerea $(n=4), N$. elongata $(n=1), N$. lactamica $(\mathrm{n}=8), N$. meningitidis $(\mathrm{n}=21), N$. polysacchareae $(\mathrm{n}=4)$, $N$. sicca $(n=1), N$. subflava $(n=10)$ and $N$. weaveri $(n=1)$, and were predominantly isolated in New South Wales, Australia during the years 2007 to 2009. 
Application to clinical samples

Following evaluation of the mosaic501-hybPCR assay, 159 clinical specimens were screened for the presence of mosaic $\mathrm{PBP}_{2}$ sequences and alterations at amino acid 501. The samples comprised DNA extracts from 62 urine specimens and 13 endocervical, eight vaginal, 74 rectal and two throat swabs that were PCR-positive for N. gonorrhoeae at the South Eastern Area Laboratory Services in Sydney, New South Wales during the first half of 2012. Samples were initially tested using the mosaic-PCR. Samples providing positive results in the mosaic-PCR were then characterised using the mosaic501-hybPCR assay.

\section{Detection limit}

A ten-fold dilution series of DNA from the N. gonorrhoeae NG0304 strain [7] in water (10E-1 to $10 \mathrm{E}-9$ ) was prepared. The dilutions were tested in duplicate in the mosaic501-hybPCR and mosaic-PCR assays above, as well as an N. gonorrhoeae duplex real-time PCR assay (NG-duplex) routinely used by our laboratory for detection of gonorrhoea and targeting the gonococcal porA pseudogene and multicopy opa genes [12]. The detection limit of each assay was determined as the lowest concentration returning positive results in both duplicates.

\section{Results}

Table 2 provides the melting temperatures for the controls (samples 1 to 4; Table 2), all isolates (samples 5 to 30; Table 2) and all clinical specimens (samples 31 to 40; Table 2) for which melting curves were obtained in the mosaic501-hybPCR assay.

\section{Mosaic501-hybPCR assay evaluation}

The results for the controls (samples 1 to 4; Table 2) showed that based on melting temperature, isolates with mosaic/A501P $\left(68.0^{\circ} \mathrm{C}\right)$ or mosaic/A501V $\left(56.5^{\circ} \mathrm{C}\right)$ could be distinguished from isolates with mosaic/A501 or mosaic/A501T $\left(58.48^{\circ} \mathrm{C}\right.$ and $58.50^{\circ} \mathrm{C}$ respectively). However, isolates with mosaic/A501 or mosaic/A501T could not be distinguished from each other given their similar melting temperatures. The latter was not considered a problem given that an isolate with a mosaic/ A501T alteration has not been described to date.

The mosaic501-hybPCR assay results for the 33 N. gonorrhoeae clinical isolates were consistent with the results of DNA sequencing. The isolates with mosaic/A501 $(n=3)$ and mosaic/A501V $(n=1)$ were correctly characterised by the mosaic501-hybPCR assay (samples 5 to 8; Table 2). No melting curves were observed for the remaining $29 \mathrm{~N}$. gonorrhoeae isolates and were consistent with all of these isolates lacking a mosaic $\mathrm{PBP} 2$ sequence.

Of the 58 non-gonococcal strains, 22 (samples 9 to 30; Table 2) provided melting curves in the mosaic501hybPCR assay; $N$. cinerea $(n=3), N$. elongata $(n=1)$, $N$. lactamica $(n=7), N$. meniningitidis $(n=3), N$. polysacchareae $(n=2)$ and $N$. subflava $(n=6)$. Of these, 19 were characterised as mosaic/A501 whereas the remaining three isolates could not be characterised on the basis that their melting curves were not consistent with any of the reference controls.

\section{Application to clinical samples}

Of the 159 clinical specimens, 10 (6 rectal swabs and 4 urine samples) provided positive results in the mosaicPCR assay. When tested by the mosaic501-hybPCR assay, all were characterised as mosaic/A501 strains (samples 31 to 40; Table 2).

\section{Detection limit}

The testing of ten-fold dilutions of DNA from the NG0304 strain showed that the mosaic501-hybPCR and mosaic-PCR assays had comparable detection limits, with both detecting to the $10 \mathrm{E}-7$ dilution. However, both these methods were 10 -fold less sensitive than the NG-duplex assay which detected to the $10 \mathrm{E}-8$ dilution.

\section{Discussion}

The fact that the $N$. gonorrhoeae F89 strain has been found in both France and Spain suggests that this may indeed be the first high-level ceftriaxone-resistant gonococcal strain spreading internationally. Enhanced surveillance for this strain is therefore warranted, particularly in Europe. The main aim of this study was to develop a real-time PCR method that could distinguish $N$. gonorrhoeae strains of the mosaic/A501P PBP2 type so that it could be used for direct screening for the N. gonorrhoeae F89 strain. Overall, the approach appears suitable for this purpose, and in fact could potentially also be used to detect strains of the mosaic/ A501V PBP2 type. When applied to 159 N. gonorrhoeae PCR-positive samples from our local Sydney (Australia) population, we found that $10 / 159$ (6.3\%) had a mosaic $\mathrm{PBP}_{2}$, but that none of these possessed the $\mathrm{A}_{501} \mathrm{P}$ or A501V alterations. These data are consistent with the fact that while isolates with ceftriaxone-reduced susceptibility are prevalent in the Australian population, no isolates exhibiting ceftriaxone MICs reflective of the Ho41 or F89 strains have yet been reported in the Australian population. Our ongoing concern is that with the speed with which $N$. gonorrhoeae isolates with the mosaic $\mathrm{PBP}_{2}$ have spread globally $[2,13]$, importation of the F89 strain remains a very real threat.

One limitation of the approach was that there were high rates of cross-reaction observed with the commensal Neisseria species, with 22 of the 58 (38\%) non-gonococcal species providing melting peaks in the mosaic501-hybPCR assay. While none of these strains were found to possess either the $\mathrm{A}_{501} \mathrm{P}$ or $\mathrm{A}_{501 \mathrm{~V}}$ alterations, the results nevertheless highlight the considerable sequence homology between gonococcal sequences associated with antimicrobial resistance and those of commensal Neisseria strains. In practical terms, this means that the method may not be suitable for use on pharyngeal specimens where commensal Neisseria species are prevalent, given that amplification of the penA of such species, together or instead 


\section{TABLE 2}

Melting temperatures for controls, isolates and clinical samples obtained in the mosaic501-hybPCR assay, which was developed to detect nucleotide substitutions leading to mosaic penicillin binding protein 2 types differing at residue 501

\begin{tabular}{|c|c|c|c|}
\hline Sample typeand number & Description & penA/PBP2 type ${ }^{a}$ & Melting temperature (call) \\
\hline \multicolumn{4}{|l|}{ Controls } \\
\hline 1. & Neisseria gonorrhoeae isolate & Mosaic/A501 & $58.48^{\circ} \mathrm{C}\left(\right.$ mosaic $\left./ \mathrm{A}_{501}{ }^{\mathrm{b}}\right)$ \\
\hline 2. & Plasmid control & Mosaic/A501T & $58.50^{\circ} \mathrm{C}$ \\
\hline 3. & Plasmid control & Mosaic/A501V & $56.50^{\circ} \mathrm{C}$ \\
\hline 4. & Plasmid control & Mosaic/A501P & $68.00^{\circ} \mathrm{C}$ \\
\hline \multicolumn{4}{|l|}{ Neisseria isolate panel } \\
\hline 5. & N. gonorrhoeae & Mosaic/A501 & $58.51^{\circ} \mathrm{C}\left(\right.$ mosaic $\left./ \mathrm{A}_{501^{\mathrm{b}}}\right)$ \\
\hline 6. & N. gonorrhoeae & Mosaic/A501 & $58.54^{\circ} \mathrm{C}\left(\right.$ mosaic $\left./ \mathrm{A}_{501} 1^{\mathrm{b}}\right)$ \\
\hline 7. & N. gonorrhoeae (Ho41) & Mosaic/A501 & $58.63^{\circ} \mathrm{C}\left(\mathrm{mosaic} / \mathrm{A}_{501^{\mathrm{b}}}\right)$ \\
\hline 8. & N. gonorrhoeae (NG0304) & Mosaic/A501V & $56.15^{\circ} \mathrm{C}\left(\mathrm{mosaic} / \mathrm{A}_{501 \mathrm{~V})}\right.$ \\
\hline 9. & N. cinerea & NA & $58.49^{\circ} \mathrm{C}\left(\right.$ mosaic $\left./ \mathrm{A}_{501} \mathrm{~b}\right)$ \\
\hline 10. & N. cinerea & NA & $58.67^{\circ} \mathrm{C}\left(\mathrm{mosaic} / \mathrm{A}_{\left.501^{\mathrm{b}}\right)}\right.$ \\
\hline 11. & N. cinerea & NA & $58.02^{\circ} \mathrm{C}\left(\right.$ mosaic $\left./ \mathrm{A}_{501} \mathrm{~b}\right)$ \\
\hline 12. & N. elongata & NA & $59.20^{\circ} \mathrm{C}\left(\mathrm{mosaic} / \mathrm{A}_{501^{\mathrm{b}}}\right)$ \\
\hline 13. & N. lactamica & NA & $58.41^{\circ} \mathrm{C}\left(\mathrm{mosaic} / \mathrm{A}_{501^{\mathrm{b}}}\right)$ \\
\hline 14. & N. lactamica & NA & $58.45^{\circ} \mathrm{C}\left(\mathrm{mosaic} / \mathrm{A}_{501^{\mathrm{b}}}\right)$ \\
\hline 15. & N. lactamica & NA & $58.49^{\circ} \mathrm{C}\left(\right.$ mosaic $\left./ \mathrm{A}_{501}{ }^{\mathrm{b}}\right)$ \\
\hline 16. & N. lactamica & NA & $58.49^{\circ} \mathrm{C}\left(\right.$ mosaic $\left./ \mathrm{A}_{501} \mathrm{~b}\right)$ \\
\hline 17. & N. lactamica & NA & $58.68^{\circ} \mathrm{C}\left(\right.$ mosaic $\left./ \mathrm{A}_{501^{\mathrm{b}}}\right)$ \\
\hline 18. & N. lactamica & NA & $58.71^{\circ} \mathrm{C}\left(\right.$ mosaic $\left./ \mathrm{A}_{501^{\mathrm{b}}}\right)$ \\
\hline 19. & N. lactamica & NA & $58.98^{\circ} \mathrm{C}\left(\right.$ mosaic $\left./ \mathrm{A}_{501} \mathrm{~b}\right)$ \\
\hline 20. & N. meniningitidis & NA & $58.96^{\circ} \mathrm{C}\left(\right.$ mosaic $\left./ \mathrm{A}_{501^{\mathrm{b}}}\right)$ \\
\hline 21. & N. meniningitidis & NA & $58.68^{\circ} \mathrm{C}\left(\right.$ mosaic $\left./ \mathrm{A}_{501^{\mathrm{b}}}\right)$ \\
\hline 22. & N. meniningitidis & NA & $53.23^{\circ} \mathrm{C}(\mathrm{NT})$ \\
\hline 23. & N. polysacchareae & NA & $58.38^{\circ} \mathrm{C}\left(\right.$ mosaic $\left./ \mathrm{A}_{501^{\mathrm{b}}}\right)$ \\
\hline 24. & N. polysacchareae & NA & $58.60^{\circ} \mathrm{C}\left(\right.$ mosaic $\left./ \mathrm{A}_{501}{ }^{\mathrm{b}}\right)$ \\
\hline 25. & N. subflava & NA & $45.75^{\circ} \mathrm{C}(\mathrm{NT})$ \\
\hline 26. & N. subflava & NA & $46.98^{\circ} \mathrm{C}(\mathrm{NT})$ \\
\hline 27. & N. subflava & NA & $58.40^{\circ} \mathrm{C}\left(\right.$ mosaic $\left./ \mathrm{A}_{501^{\mathrm{b}}}\right)$ \\
\hline 28. & N. subflava & NA & $58.51^{\circ} \mathrm{C}\left(\right.$ mosaic $\left./ \mathrm{A}_{501^{\mathrm{b}}}\right)$ \\
\hline 29. & N. subflava & NA & $58.55^{\circ} \mathrm{C}\left(\right.$ mosaic $\left./ \mathrm{A}_{501} \mathrm{~b}\right)$ \\
\hline 30. & N. subflava & NA & $58.92^{\circ} \mathrm{C}\left(\right.$ mosaic $\left./ \mathrm{A}_{501} 1^{\mathrm{b}}\right)$ \\
\hline \multicolumn{4}{|c|}{ PCR-positive clinical samplesc ${ }^{c}$} \\
\hline 31. & Rectal swab & NA & $58.57^{\circ} \mathrm{C}\left(\right.$ mosaic $\left./ \mathrm{A}_{501^{\mathrm{b}}}\right)$ \\
\hline 32. & Rectal swab & NA & $58.68^{\circ} \mathrm{C}\left(\right.$ mosaic $\left./ \mathrm{A}_{501^{\mathrm{b}}}\right)$ \\
\hline 33. & Rectal swab & NA & $58.78^{\circ} \mathrm{C}\left(\right.$ mosaic $\left./ \mathrm{A}_{501}{ }^{\mathrm{b}}\right)$ \\
\hline 34. & Rectal swab & NA & $58.83^{\circ} \mathrm{C}\left(\right.$ mosaic $\left./ \mathrm{A}_{501} 1^{\mathrm{b}}\right)$ \\
\hline 35. & Rectal swab & NA & $58.84^{\circ} \mathrm{C}\left(\mathrm{mosaic} / \mathrm{A}_{501^{\mathrm{b}}}\right)$ \\
\hline 36. & Rectal swab & NA & $59.13^{\circ} \mathrm{C}\left(\right.$ mosaic $\left./ \mathrm{A}_{501^{\mathrm{b}}}\right)$ \\
\hline 37. & Urine sample & NA & $58.57^{\circ} \mathrm{C}\left(\right.$ mosaic $\left./ \mathrm{A}_{501} \mathrm{~b}\right)$ \\
\hline 38. & Urine sample & NA & $58.60^{\circ} \mathrm{C}\left(\right.$ mosaic $\left./ \mathrm{A}_{501^{\mathrm{b}}}\right)$ \\
\hline 39. & Urine sample & NA & $58.61^{\circ} \mathrm{C}\left(\right.$ mosaic $\left./ \mathrm{A}_{501^{\mathrm{b}}}\right)$ \\
\hline 40. & Urine sample & NA & $58.63^{\circ} \mathrm{C}\left(\right.$ mosaic $\left./ \mathrm{A}_{501^{\mathrm{b}}}\right)$ \\
\hline
\end{tabular}

NA: not available; NT: not typed, as melting temperature was not consistent with any of the reference controls; PBP2: penicillin binding protein 2; PCR: polymerase chain reaction.

a Based on DNA sequencing. The mosaic PBP2 types are designated by 'mosaic' followed by details of the particular residue or mutation at position 501 of the protein sequence.

b It should be noted that the assay cannot distinguish between mosaic/A501 and mosaic/A501T.

c These samples were positive by Neisseria gonorrhoeae PCR as well as the mosaic-PCR assay. 
of penA of $N$. gonorrhoeae, could potentially interfere with characterisation by melting curve analysis. A second limitation of the mosaic501-hybPCR and mosaicPCR assays, as shown by the detection limit studies, is that they are less sensitive than diagnostic N. gonorrhoeae NAAT methods, such as the NG-duplex method tested in this study. Hence, the approach will not be able to characterise all N. gonorrhoeae NAAT, particularly samples with very low N. gonorrhoeae DNA loads. It should also be noted that in addition to a 'CCG' codon, an $\mathrm{A}_{501} \mathrm{P}$ alteration may also arise via ' $\mathrm{CCT}$ ', ' $C C C$ ' or 'CCA' and would therefore not be identified by the current method. We do not however consider this a major limitation in the context of screening for the F89 strain, which is known to possess the 'CCG' codon.

In summary, our results show that the mosaic501-hybPCR assay can be readily used to detect the presence of the mosaic/A501P PBP2 alteration, and therefore, when used in combination with mosaic-PCR, could be used for direct detection of the N. gonorrhoeae F89 strain in non-cultured clinical samples. Use of the assay could considerably strengthen bacterial culture-based investigations into the broader prevalence, if any, of the F89 strain in Europe. Likewise, for settings where AMR surveillance gaps exist because of increased use of NAAT for gonorrhoea diagnosis or where the scope for bacterial culture is limited, such methods also demonstrate considerable potential of molecular technology to enhance $N$. gonorrhoeae antimicrobial resistance surveillance.

\section{Acknowledgements}

This study was conducted as part of the reference work of the National Neisseria Network, Australia.

This study was supported by the Queensland Children's Medical Research Institute, Development Project Grant 50059 .
References

1. Ohnishi M, Golparian D, Shimuta K, Saika T, Hoshina S, Iwasaku K, et al. Is Neisseria gonorrhoeae initiating a future era of untreatable gonorrhea?: detailed characterization of the first strain with high-level resistance to ceftriaxone. Antimicrob Agents Chemother. 2011;55(7): 3538-45. http://dx.doi.org/10.1128/AAC.00325-11 PMid:21576437 PMCid:3122416

2. Unemo M, Golparian D, Nicholas R, Ohnishi M, Gallay A, Sednaoui P. High-level cefixime- and ceftriaxone-resistant N. gonorrhoeae in France: novel penA mosaic allele in a successful international clone causes treatment failure. Antimicrob Agents Chemother. 2012;56(3):1273-80. http://dx.doi.org/10.1128/AAC.05760-11 PMid:22155830 PMCid:3294892

3. Cámara J, Serra J, Ayats J, Bastida T, Carnicer-Pont D, Andreu A, et al. Molecular characterization of two high-level ceftriaxoneresistant Neisseria gonorrhoeae isolates detected in Catalonia, Spain. J Antimicrob Chemother. 2012;67(8):1858-60. http://dx.doi.org/10.1093/jac/dks162 PMid:22566592

4. Takahata S, Senju N, Osaki Y, Yoshida T, Ida T. Amino acid substitutions in mosaic penicillin-binding protein 2 associated with reduced susceptibility to cefixime in clinical isolates of Neisseria gonorrhoeae. Antimicrob Agents Chemother. 2006;50(11):3638-45. http://dx.doi.org/10.1128/AAC.00626-06 PMid:16940068 PMCid:1635225

5. Whiley DM, Limnios EA, Ray S, Sloots TP, Tapsall JW. Diversity of penA alterations and subtypes in Neisseria gonorrhoeae strains from Sydney, Australia, that are less susceptible to ceftriaxone. Antimicrob Agents Chemother. 2007:51(9):3111-16. http://dx.doi.org/10.1128/AAC.00306-07 PMid:17591846 PMCid:2043202

6. Tomberg J, Unemo M, Davies C, Nicholas RA. Molecular and structural analysis of mosaic variants of penicillin-binding protein 2 conferring decreased susceptibility to expandedspectrum cephalosporins in Neisseria gonorrhoeae : role of epistatic mutations. Biochemistry. 2010;49(37):806270. http://dx.doi.org/10.1021/bi101167x PMid:20704258 PMCid:2939205

7. Ohnishi M, Watanabe Y, Ono E, Takahashi C, Oya H, Kuroki T, et al. Spread of a chromosomal cefixime-resistant penA gene among different Neisseria gonorrhoeae lineages. Antimicrob Agents Chemother. 2010;54(3):1060-7. http://dx.doi. org/10.1128/AAC.01010-09 PMid:20028823 PMCid:2826007

8. Goire N, Ohnishi M, Limnios AE, Lahra MM, Lambert SB, Nimmo $\mathrm{GR}$, et al. Enhanced gonococcal antimicrobial surveillance in the era of ceftriaxone resistance: a real-time PCR assay for direct detection of the Neisseria gonorrhoeae Ho41 strain. J Antimicrob Chemother. 2011;67(4):902-5. http://dx.doi. org/10.1093/jac/dkr549 PMid:22207596

9. Goire N, Freeman K, Lambert SB, Nimmo GR, Limnios AE, Lahra $M M$, et al. The influence of target population on nonculturebased detection of markers of Neisseria gonorrhoeae antimicrobial resistance. Sex Health. 2012;9(5):422-9. http://dx.doi.org/10.1071/SH12026 PMid:23036167

10. Ochiai S, Ishiko H, Yasuda M, Deguchi T. Rapid detection of the mosaic structure of the Neisseria gonorrhoeae penA Gene, which is associated with decreased susceptibilities to oral cephalosporins. J Clin Microbiol. 2008;46(5):1804-10. http://dx.doi.org/10.1128/JCM.01800-07 PMid:18367575 PMCid:2395096

11. Whiley DM, Jacob K, Nakos J, Bletchly C, Nimmo GR, Nissen MD, et al. Improved detection of genetic markers of antimicrobial resistance by hybridization probe-based melting curve analysis using primers to mask proximal mutations: examples include the influenza $\mathrm{H}_{275} \mathrm{Y}$ substitution. J Antimicrob Chemother. 2012;67(6):1375-9. http://dx.doi.org/10.1093/jac/dks040 PMid:22334604

12. Goire N, Nissen MD, LeCornec GM, Sloots TP, Whiley DM. A duplex Neisseria gonorrhoeae real-time polymerase chain reaction assay targeting the gonococcal porA pseudogene and multicopy opa genes. Diagn Microbiol Infect Dis. 2008;61(1):612. http://dx.doi.org/10.1016/j.diagmicrobio.2007.12.007 PMid: 18248938

13. Tapsall JW. Neisseria gonorrhoeae and emerging resistance to extended spectrum cephalosporins. Curr Opin Infect Dis. 2009;22(1):87-91. http://dx.doi.org/10.1097/ QCO.obo13e328320a836 PMid:19532086 